Western North American Naturalist 67(4), (C) 2007, pp. 492-502

\title{
GROWTH AND DEMOGRAPHY OF ONE POPULATION OF THE LIZARD SCELOPORUS MUCRONATUS MUCRONATUS
}

\author{
Angela M. Ortega-León ${ }^{1}$, Emily R. Smith²,4 J. Jaime Zúñiga-Vega ${ }^{3}$, \\ and Fausto R. Méndez-de la Cruz ${ }^{1}$
}

\begin{abstract}
We report on growth and demography of Sceloporus mucronatus mucronatus, a lizard subspecies endemic to central Mexico. We characterize the life history of this subspecies, provide quantitative information relevant to conservation, and add to the growing literature on the diversity of life histories in the genus Sceloporus. We calculated body growth rates and fitted them to the Von Bertalanffy, the logistic-by-length, and the logistic-by-weight growth models. The Von Bertalanffy model provided the best fit, and we used it to analyze the growth pattern. Growth rates were similar during the 1st year of life in both sexes, but after that point males grew faster and reached maturity earlier ( 20 months) than females (31 months). We used a population projection matrix to model population dynamics during 2003-2004 and found a positive population growth rate $(\lambda=1.769)$. However, based on the projected stable size-class vector $(w)$, this population does not appear to have reached stability, and it might be currently experiencing considerable interannual fluctuations. Elasticity values showed that the transition from the juvenile stage to the 1st adult stage was the vital rate that contributes the most to population growth rate, followed by fecundity and stasis of the 1st reproductive category. While total elasticities for demographic processes were similar, elasticities per size class showed the relatively high importance of small adults in comparison to juveniles and large adults. The restriction of this endemic subspecies to central Mexico, where human activities and consequent habitat destruction are increasing, demands further quantitative evaluation and monitoring of populations, even though our results indicate a potential for population growth.
\end{abstract}

Key words: body growth, elasticity analysis, life history traits, Mexico, population dynamics, Sceloporus mucronatus mucronatus, transition matrix.

Species of the lizard genus Sceloporus exhibit a wide variety of life history strategies that range from early maturation, high fecundity, rapid body growth, and short lifespan to delayed maturation, low fecundity, slow body growth, and relatively long lifespan with an apparent continuum of intermediate strategies (Tinkle et al. 1970, Dunham et al. 1988, Clobert et al. 1998). Even though considerable information exists about life histories and population dynamics of several species from this genus (e.g., Tinkle et al. 1993, Niewiarowski et al. 2004, Ramírez-Bautista et al. 2004), a complete understanding of the evolution of life history traits within this highly diverse group requires a complete description of such traits for all the species in the genus, as well as for distinct populations of species with wide geographic distributions.

Beyond life history descriptions, the analysis of population dynamics provides basic information that is critical to evaluating conservation status of natural populations (Crouse et al.
1987, Contreras and Valverde 2002). In spite of the great diversity and endemism of Sceloporus species in Mexico (approximately 45 endemic species out of 80 species; Flores-Villela 1993, Pough et al. 2004), only 24 species have conservation status according to the Mexican environmental agency (Secretaría de Medio Ambiente y Recursos Naturales, NOM-059-ECOL-2001). Such conservation categories have been based mostly on distributional and observed abundance data rather than on formal quantitative analyses.

Herein, we report data on the growth, survival, and fecundity of 1 population of Sceloporus mucronatus mucronatus, a subspecies endemic to central Mexico that currently has no conservation status. We fitted body growth models and analyzed population dynamics using a projection matrix approach (Caswell 2001). Our main goals were to characterize the life history of this subspecies by providing the quantitative information necessary to evaluate its conservation status, and to contribute

\footnotetext{
${ }^{1}$ Laboratorio de Herpertología, Instituto de Biología, Universidad Nacional Autónoma de México, Distrito Federal 04510, México. ${ }^{2}$ Department of Plant and Wildlife Sciences, Brigham Young University, Provo, UT 84602.

${ }^{3}$ Evolutionary Ecology Laboratories, Department of Integrative Biology, Brigham Young University, Provo, UT 84602.

${ }^{4}$ Corresponding author. E-mail: vegi.emi@gmail.com
} 
knowledge about the diversity of life histories in the genus Sceloporus.

\section{STUDY AREA}

We delimited a 1 ha plot in the national park El Ajusco, south of Mexico City at 3375 m elevation $\left(19^{\circ} 12^{\prime} \mathrm{N}, 99^{\circ} 16^{\prime} \mathrm{W}\right)$. This site was composed mainly of grassland punctuated with numerous volcanic rocks, which provided crevices that served as safe refuges for these saxicolous lizards. Mean annual temperature was $7.3^{\circ} \mathrm{C}$ with minimum temperatures near $0^{\circ} \mathrm{C}$ during the winter. Precipitation varied within the year: August was the wettest month $(293.4 \mathrm{~mm})$ and May was the driest $(9.7 \mathrm{~mm}$; Uribe-Peña et al. 1999).

\section{Methods}

\section{Study Species}

Sceloporus mucronatus mucronatus is endemic to central Mexico. It inhabits diverse environments usually above $2000 \mathrm{~m}$, from pine forests to xeric regions. It is saxicolous, diurnal, viviparous, and markedly sexually dimorphic with males being significantly larger than females (Toledo 2005). Females and males are highly territorial and remain loyal to a small area during most of their lives (Salazar 2003, Toledo 2005). Both sexes reach sexual maturity at $63 \mathrm{~mm}$ snout-vent length (SVL) and show seasonal reproductive activity; however, in the population we studied, females and males differ in the time of peak gonadal activity (asynchrony in their reproductive cycles). Litter size varies within and among populations, ranging from 2 to 12 neonates (Méndez- de la Cruz et al. 1988, 1994, Villagrán-Santa Cruz et al. 1994, Salazar 2003).

\section{Field Methods}

We visited the study site on 13 occasions between June 2003 and October 2004, with at least 30 days separating the visits. On each visit we sampled the study plot extensively, including all possible crevices where lizards tend to hide or overwinter, to capture the highest number of individuals. Lizards were captured by noose or by hand, and SVL, body mass, and sex were recorded for every capture. At 1st capture each lizard was uniquely marked by toe-clipping, which allowed for identification upon subsequent recapture.

\section{Growth Model}

We calculated body growth rates for 62 individuals: 37 females and 25 males. Growth rate was defined as the difference in length between 2 captures divided by the number of days elapsed between such capture events. This yielded rates of length change $\left(\mathrm{mm} \cdot\right.$ day $\left.^{-1}\right)$ for individual lizards. Even though we had the opportunity to estimate several growth rates per individual (1 for each pair of captures), we estimated just 1 growth rate per individual to avoid nonindependence of the data. In cases where we had $>2$ captures per organism, the recapture interval used for the calculation of its corresponding growth rate was randomly selected.

Using nonlinear regression methods, we fitted the Von Bertalanffy (1951, 1957), the logistic-by-length, and the logistic-by-weight growth models (Schoener and Schoener 1978, Andrews 1982) to the relationship between estimated growth rates and the corresponding average sizes at which they were calculated. The differential equations of these models were used to estimate 2 main growth parameters for each sex: the asymptotic body length $\left(A_{1}\right)$ and the "characteristic growth parameter" $(r$; see Dunham 1978 and Schoener and Schoener 1978 for detailed formulas of the growth models). Conservative 95\% “support plane" confidence intervals were constructed around the estimated parameters according to Schoener and Schoener (1978). We considered a difference between sexes in the growth parameters $\left(A_{1}\right.$ and $r$ ) significant if their corresponding $95 \%$ support plane confidence intervals did not overlap.

We chose the best model as the one yielding the smallest residual mean squares $(R M S)$ and highest $R^{2}$ values (Dunham 1978, Zúñiga-Vega et al. 2005). Once identified, the solution of the differential equation of such best model and its corresponding estimated growth parameters was used to construct growth curves relating size and age (Dunham 1978, Schoener and Schoener 1978). Using age estimates based on size derived from the growth curves, we determined age at maturity for each sex (i.e., predicted ages for $63 \mathrm{~mm}$ SVL). To test the fit of the growth curves, we used growth trajectories of lizards of known age (born in the laboratory and then followed in the field) and of lizards whose ages were assigned according to the age estimates of the growth curve (also followed in the field). Additionally, we used student 


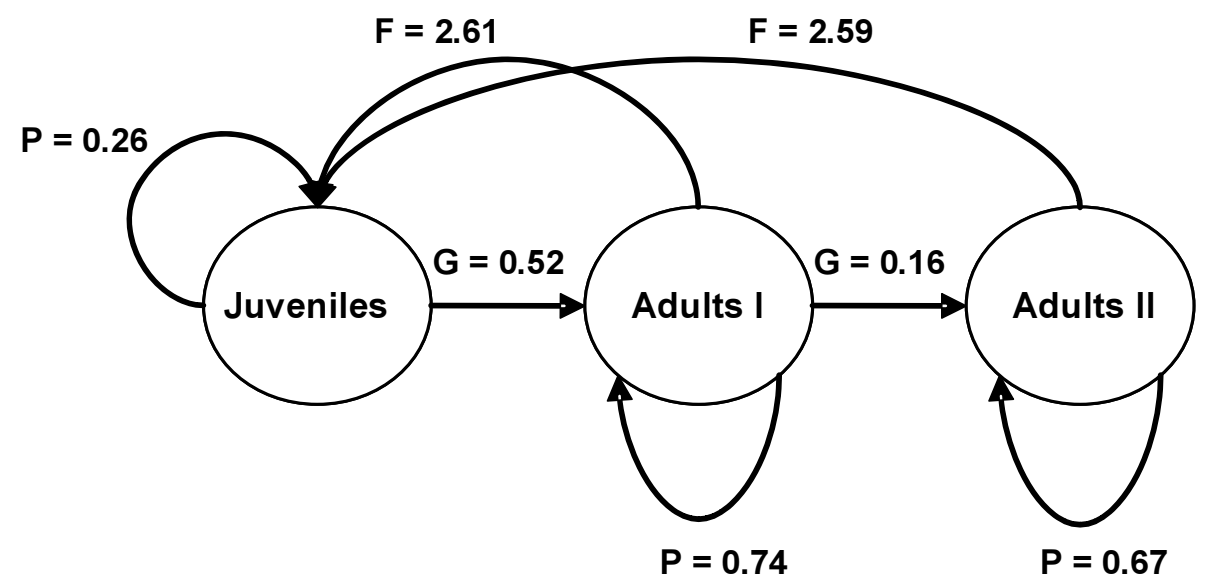

Fig. 1. Life-cycle graph for the population of Sceloporus mucronatus mucronatus that we studied. Nodes represent stage classes (juveniles, adults I, and adults II). Arrows and their associated values represent transition probabilities (in the case of growth or stasis) or contributions (in the case of fecundities) made by individuals in a specific category to other catagories. $\mathrm{F}=$ fecundity, $\mathrm{G}=$ growth, $\mathrm{P}=$ permanence or stasis.

$t$ tests to compare individual growth rates between sexes over 3 distinct ontogenetic periods: during the 1st year of life, between 1 year of age and sexual maturity, and during adulthood.

\section{Survival Estimates}

We calculated annual survival rates as the proportion of resident lizards (individuals with $>1$ recapture; Ballinger 1973) observed in summer 2003 that were recaptured during or after summer 2004. The use of only resident lizards for estimating survival avoids the inclusion of migratory animals and seems adequate for territorial organisms with relatively low mobility (Zúñiga-Vega et al. 2007). Furthermore, in the last months of the study all new marks corresponded to newborn lizards, which indicated that we marked almost the entire population and that our survival estimates were accurate because they were calculated only from effectively resident individuals.

\section{Matrix Analyses}

The population dynamics of Sceloporus mucronatus mucronatus were evaluated by constructing a population projection matrix for 2003-2004. For the stage-classified matrix, this species was categorized into 3 stage categories according to SVL: juveniles ( $\leq 63 \mathrm{~mm})$, adults I $(64-77.5 \mathrm{~mm})$, and adults II $(>77.5 \mathrm{~mm})$. Individuals of this species were considered reproductively mature when they reached $63 \mathrm{~mm}$
(Méndez-de la Cruz et al. 1988, 1994, VillagránSanta Cruz et al. 1994, Salazar 2003); thus, all individuals below this size at maturity were presumed to be juveniles. The distinction between adults I and adults II was based on the size at which we began to register zero growth (77.5 mm SVL). The 2 possible fates for each category included survival with growth to the next stage (transition) or survival without growth (permanence or stasis; Caswell 2001). Probabilities of each of these fates, based on observed proportions, were derived directly from estimated survival rates.

To estimate litter size, we collected 30 pregnant females during February, March, and April 2003 from a site located $10 \mathrm{~km}$ from the study plot. These females were maintained alive in the laboratory until parturition, at which time litter size per female was recorded. Immediately after parturition, females and offspring were returned to the field. Mean litter size per stage category was calculated from these laboratory data. Fecundity entries of the transition matrix (1st row) were calculated by multiplying estimated litter sizes by the survival of the corresponding adult category to account for the probability of females surviving 1 year before they reach the reproductive season. These fecundity estimates correspond to a postbreeding type according to Caswell (2001).

The projection matrix was constructed using the survival, growth, and fecundity rates of each of the size classes for the entries in the matrix. 
TABLE 1. Summary of parameter estimation for the 3 growth models we used: Von Bertalanffy (VB), logistic-by-length $(\mathrm{LBL})$, and logistic-by-weight $(\mathrm{LBW})$. Results are shown separately for females and males. $R^{2}=$ coefficient of determination, $R M S=$ residual mean square, $A_{1}=$ asymptotic body size, and $r=$ characteristic growth parameter. $A_{1}$ and $r$ are shown with their associated $95 \%$ support plane confidence intervals.

\begin{tabular}{ccccc}
\hline Model & $R^{2}$ & $R M S$ & $A_{1}$ & $r$ \\
\hline Females & & & & \\
VB & 0.4133 & 0.00012 & $91.57 \pm 4.45$ & $0.00082 \pm 0.0003$ \\
LBL & 0.3443 & 0.00014 & $88.32 \pm 6.14$ & $0.00134 \pm 0.0004$ \\
LBW & 0.2480 & 0.00016 & $87.98 \pm 5.34$ & $0.00174 \pm 0.0005$ \\
Males & & & $114.29 \pm 15.53$ & $0.00082 \pm 0.0004$ \\
VB0 & 0.3852 & 0.00030 & $103.71 \pm 8.10$ & $0.00177 \pm 0.0006$ \\
LBL & 0.3388 & 0.00033 & $101.10 \pm 6.69$ & $0.00262 \pm 0.0009$ \\
LBW & 0.2474 & 0.00038 & & \\
\hline
\end{tabular}
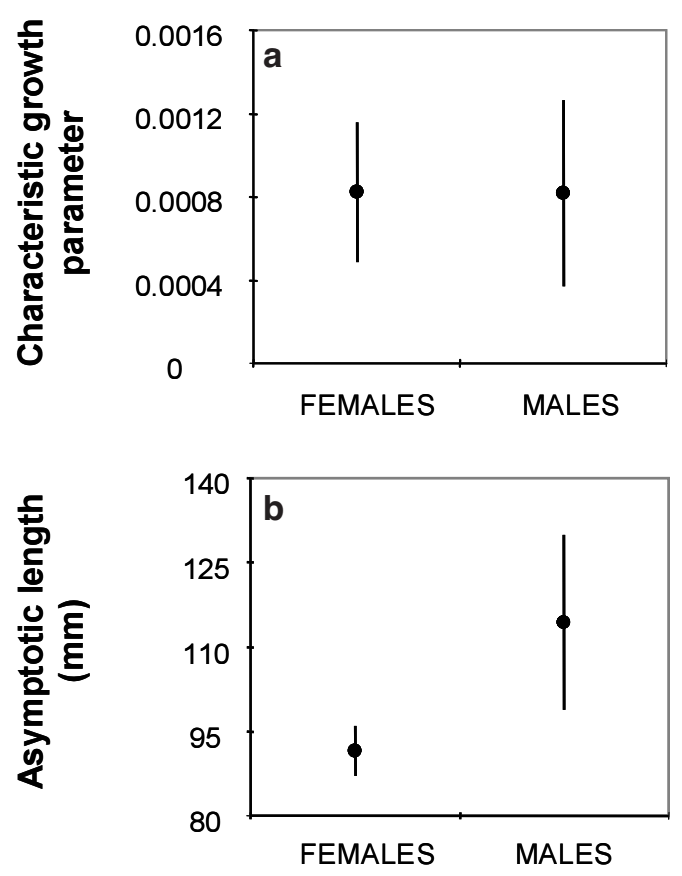

Fig. 2. Comparisons between sexes of the characteristic growth parameter (a) and of the asymptotic length (b), both estimated by the Von Bertalanffy growth model. Ninetyfive percent support plane confidence intervals are shown.

We constructed a $3 \times 3$ transition matrix based on the life-cycle graph of the population (Fig. 1). Each of the entries in the matrix $\left(a_{i j}\right)$ represents the probability that individuals in 1 size class ( $j=$ columns) transition or contribute (via offspring) to another (or the same through permanence) size class ( $i=$ rows; Caswell 2001). Entries representing permanence, or staying in the same size class (stasis), are found along the main diagonal of the matrix, whereas entries in the subdiagonal represent growth to the next class (both derived from observed survival rates). Thus, the survival rates observed for each size class were partitioned into 2 processes: surviving and remaining in the same size class (stasis), and surviving and growing to a superior size class (growth). Fecundity entries are found in the 1st row of the matrix.

We used the power method to obtain the dominant eigenvalue for the projection matrix (Caswell 2001), which is interpreted as the finite rate of population increase $(\lambda)$. We also obtained the stable size-class distribution, represented by the right eigenvector associated to $\lambda(w)$, and the size-specific reproductive values, represented by the left eigenvector $(v)$ associated to $\lambda$ (Caswell 2001). We tested for differences between projected ( $w$ eigenvector) and observed stage-class distributions using a $\chi^{2}$ test. A confidence interval for $\lambda$ was constructed according to the analytical method proposed by Alvarez-Buylla and Slatkin (1991).

We calculated an elasticity matrix (de Kroon et al. 1986, 2000, Caswell 2001) to estimate the relative change in $\lambda$ that would result from relative changes in matrix entries. The entries in the elasticity matrix were calculated using the following equation: $e_{i j}=s_{i j} \cdot\left(a_{i j} / \lambda\right)$, where $s_{i j}$ is the absolute sensitivity of $\lambda$ to changes in the matrix entries $\left(s_{i j}=\partial a_{i j} / \partial \lambda\right)$. Elasticities are standardized sensitivities, and thus can be used to compare the relative contribution (i.e., relative importance) of each matrix entry to population growth rate (de Kroon et al. 1986, 2000, Caswell 2001). All entries in the elasticity matrix sum to unity (Mesterton-Gibbons 1993), and this proportionality allowed us to determine the relative contribution of each demographic process (growth, stasis, and fecundity), as well as the relative contribution of each 


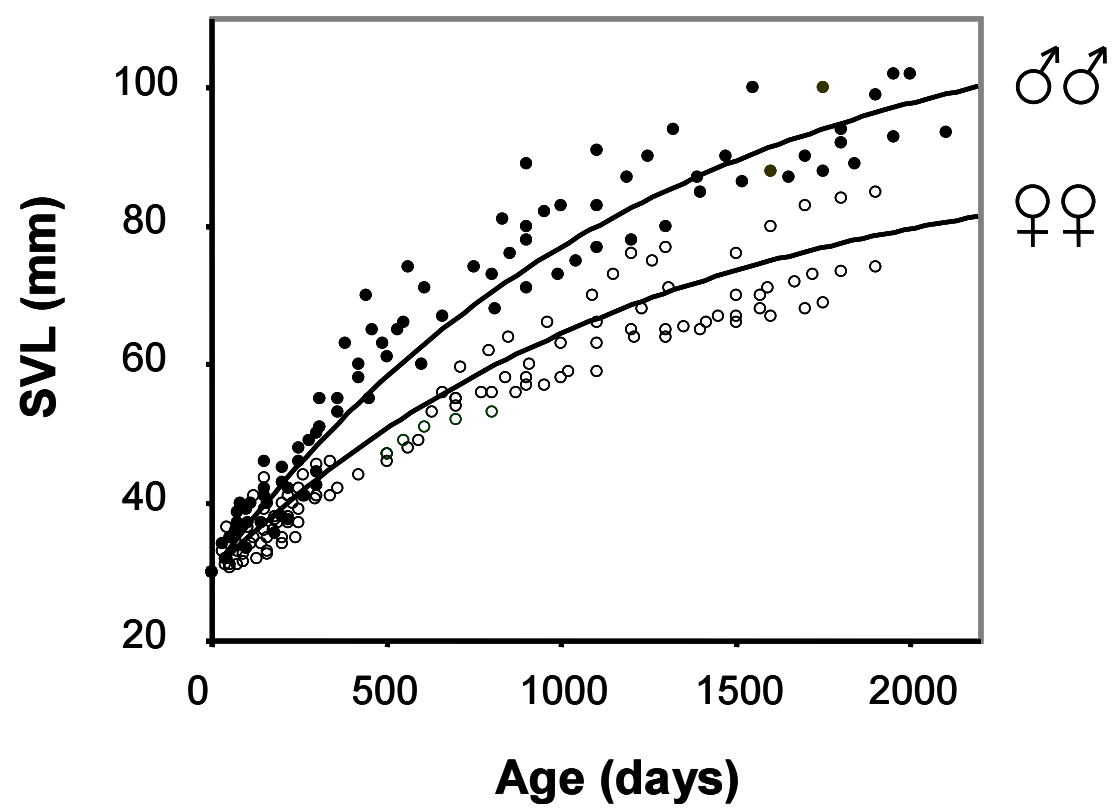

Fig. 3. Constructed growth curves for Sceloporus mucronatus mucronatus. The upper curve is for males and the lower curve is for females. Circles depict observed growth trajectories of lizards of known or assigned age. Closed circles represent males and open circles represent females. Individual lizards occur more than once in this figure. SVL = snout-vent length.

size class (juveniles, adults I, and adults II), to the growth rate of the population by summing elasticities corresponding to each category or process of interest (Silvertown et al. 1993).

\section{RESULTS}

\section{Body Growth}

The Von Bertalanffy growth model provided the best fit to our growth data in both sexes (Table 1). Thus, we decided to use this model to describe and analyze the growth pattern. According to the confidence intervals constructed around the growth parameters $(r$ and $A_{1}$ ) estimated by the Von Bertalanffy model, females and males did not show significant differences in the "characteristic growth parameter" $(r$; females $=0.00082 \pm 0.0003, n=$ 37 ; males $=0.00082 \pm 0.0004, n=25$; Fig. $2 \mathrm{a}$, Table 1). However, confidence intervals for the asymptotic lengths $\left(A_{1}\right)$ estimated by the same model did not overlap, indicating a significant difference between sexes, with males reaching a larger asymptotic length $\left(A_{1}\right.$; females $91.57 \pm$ 4.45, $n=37$; males 114.29 $\pm 15.53, n=25$; Fig. 2b, Table 1). Observed average size of adult females in the population was $75.2 \pm$
$0.75 \mathrm{~mm}$ SVL $\left(s_{\bar{x}} ; n=86\right)$ with an observed maximum of $91 \mathrm{~mm} \mathrm{SVL}$, whereas in adult males, observed mean size was $84.3 \pm 1.4 \mathrm{~mm}$ SVL $(n=60)$ with an observed maximum of $104 \mathrm{~mm}$ SVL.

We constructed a growth curve for each sex because of this intersexual size difference (Fig. 3). Variation in observed growth trajectories around the constructed growth curves was lowest for early ages and then rose as age increased. More specifically, individual growth rates were similar between sexes during the 1st year of life $\left(s_{\bar{x}}\right.$ : females $0.038 \pm 0.0034 \mathrm{~mm}$. day $^{-1}, n=7$; males $0.048 \pm 0.0057 \mathrm{~mm} \cdot$ day $^{-1}$, $n=6 ; t_{11}=-1.42, P=0.18$ ). But after this 1st year, males grew more rapidly, reaching larger sizes than females of the same age (within 1 year of age and sexual maturity: females 0.012 $\pm 0.0031 \mathrm{~mm} \cdot$ day $^{-1}, n=5$; males $0.024 \pm$ $0.0021 \mathrm{~mm} \cdot$ day $^{-1}, n=5 ; t_{8}=-3.31, P=0.01$; adults: females $0.009 \pm 0.0036 \mathrm{~mm} \cdot \mathrm{day}^{-1}, n$ $=9$; males $0.023 \pm 0.0040 \mathrm{~mm} \cdot$ day $^{-1}, n=16$; $\left.t_{23}=-2.33, P=0.03\right)$. Estimated ages at maturity (corresponding to a size of $63 \mathrm{~mm} \mathrm{SVL}$ in both sexes; Méndez-de la Cruz et al. 1988, 1994, Villagrán-Santa Cruz et al. 1994) were 31 months for females and 20 months for males, based on the growth curves. 
TABLE 2. Population projection matrix and main demographic results for the Sceloporus mucronatus mucronatus population during the $2003-2004$ transition. The corresponding $\lambda$ value is shown in the footnote $( \pm 95 \%$ confidence interval $)$ a: $q_{x}=$ mortality per size class, $n_{x}=$ number of resident lizards per size class from which transition probabilities were calculated, $w=$ projected stable size class distribution, $v=$ size-specific reproductive values.

\begin{tabular}{lcccccc}
\hline & Juveniles & Adults I & Adults II & $n_{x}$ & $w$ & $v$ \\
\hline Juveniles & 0.261 & 2.613 & 2.593 & 23 & 0.634 & 1 \\
Adult I & 0.522 & 0.737 & 0 & 19 & 0.320 & 2.891 \\
Adult II & 0 & 0.158 & 0.667 & 27 & 0.046 & 2.352 \\
$q_{x}$ & 0.217 & 0.105 & 0.333 & & & \\
\hline a & & & & &
\end{tabular}

TABLE 3. Elasticity matrix corresponding to the transition matrix for the Sceloporus mucronatus mucronatus population. Highest elasticities are shown in italics.

\begin{tabular}{lccc}
\hline 2003-2004 & Juveniles & Adults I & Adults II \\
\hline Juveniles & 0.056 & 0.284 & 0.040 \\
Adults I & 0.324 & 0.231 & 0 \\
Adults II & 0 & 0.040 & 0.024 \\
\hline
\end{tabular}

TABLE 4. Elasticities per demographic process and size class corresponding to the projection matrix for the Sceloporus mucronatus mucronatus population for 20032004 .

\begin{tabular}{lccc}
\hline $\begin{array}{l}\text { Demographic } \\
\text { process }\end{array}$ & Elasticity & Size class & Elasticity \\
\hline Fecundity & 0.324 & Juveniles & 0.380 \\
Growth & 0.364 & Adults I & 0.555 \\
Stasis & 0.312 & Adults II & 0.065 \\
\hline
\end{tabular}

Fecundity and Survival

Mean litter sizes estimated from captive females were $2.92 \pm 0.17\left(s_{\bar{x}}\right)$ for adults I $(n=15$ females) and $3.89 \pm 0.29$ for adults II $(n=15$ females). The relationship between female SVL and litter size was represented by the following equation: litter size $=-2.43+0.08$ SVL. The slope $(0.08)$ was significantly different from $0(P=0.003)$. Estimated annual survival rates of resident lizards were 0.783 for juveniles, 0.895 for adults I, and 0.666 for adults II. Overall annual survival rate, estimated by pooling data of all size classes, was 0.781 .

\section{Matrix Analyses}

The projection matrix (Table 2) yielded a population growth rate significantly above unity $(\lambda=1.769$ with a confidence interval from 1.376 to 2.162 ). The projected stable size-class distribution (vector $w$ ) was significantly different from the observed population structure $\left(\chi^{2}\right.$ $=127.5, P<0.001)$. The highest reproductive value (2.89) was observed in the adults I cate- gory followed by the reproductive value of adults II (2.35; Table 2).

The highest elasticity value (Table 3 ) corresponded to growth of juveniles to the adults I size class (0.323). Elasticity of fecundity of adults I was the next highest (0.284), followed by their stasis or permanence in the adults I size class $(0.231)$. The lowest estimates of elasticity corresponded to permanence or stasis of adults II (0.024) and then slightly higher elasticity values for fecundity of adults II (0.0403) and growth of adults I to adults II (0.0403). When elasticities were considered at a demographic process level (Table 4), all 3 processes (fecundity, growth, and stasis) contributed to $\lambda$ nearly equivalently, with the highest elasticity value being for growth (0.364), followed by fecundity (0.324), and then by stasis (0.312). However, when elasticities were summed for size classes, the adults I class had the greatest impact on the growth of the population (0.555), whereas juveniles had a proportionately lesser impact (0.38) and adults II had the lowest (0.065; Table 4).

\section{Discussion}

\section{Body Growth}

Sexually dimorphic species such as $S . m$. mucronatus (Toledo 2005) usually show dissimilar growth patterns between sexes (Andrews 1982, Stamps 1993). In this population, growth rates appear to be similar in both sexes early in life (during the 1st year), but soon thereafter, males accelerate the rate of body growth, reaching larger sizes than females of the same age. In addition, the asymptotic SVL of males is significantly larger. In consequence, and considering that both sexes mature at the same size (63 mm SVL; Méndez-de la Cruz et al. 1988, 1994, Villagrán-Santa Cruz et al. 1994, Salazar 2003), males become reproductive considerably earlier in life-at 20 
months compared to 31 months for maturation of females. This early maturity in males and the notably larger size that they can reach compared to females (114.29 $\mathrm{mm}$ SVL in males vs. $91.57 \mathrm{~mm}$ SVL in females) can be explained by sexual selection in which large, earlymaturing males might have better mating opportunities (Hedrick and Temeles 1989, Shine 1989).

In species with male-male competition, body size is usually the primary factor determining breeding success (Stamps 1993, 1999). In lizards, sexual dimorphism in size, with males being larger than females, is commonly associated with intrasexual competition for obtaining females, and larger males usually have a considerable advantage (Dunham et al. 1978, Vitt 1982, Anderson and Vitt 1990, Stamps 1999). In squamate reptiles with polygynous mating systems and with intrasexual competition for mates, males tend to delay maturation in order to reach a relatively large size (Stearns 1992). However, in S. m. mucronatus the strategy seems to be accelerated growth rates that result in early maturity. Interestingly, even though males mature considerably earlier than females, the ability to compete for mates at such size (63 mm SVL) is low. Based on intense behavioral observations in this population, only males larger than $73 \mathrm{~mm}$ SVL have success in establishing territories (A.M. Ortega-León unpublished data), which in turn appears to provide them with a considerable number of breeding opportunities (Olsson and Madsen 1998). Therefore, it is possible that small mature males, without the appropriate size for direct competition, exhibit alternative strategies for obtaining mates.

In addition, and based on the fact that young adults show higher survivorship than older adults (0.895 for adults I vs. 0.666 for adults II), sexual selection might also favor maturity in males at an early age because mating opportunities for young males might exist early in the mating season because of mortality of some large males in the population. This argument also supports selection for large size even in recently mature males. Maturing at an early age but with increased size should result from competition among young males for a very limited number of breeding opportunities. Sexual selection also favors large ultimate size because, among those males that do survive, size likely continues to determine relative mat- ing success. In summary, 2 things face recently matured males for which a relatively large size might be helpful: (1) They have to compete with established large males. For this, they are at a very large disadvantage and likely obtain matings only when a large male disappears from the population or by using an alternative strategy such as being a "sneak male" (Gross 1996, Sinervo and Lively 1996). (2) Given the limited opportunities to move into a vacated territory or to be successful as a sneak male, recently matured males have to compete with the other young males that are entering the breeding population and trying to use the same strategies.

We recognize that the results of the body growth analysis should be interpreted carefully, mostly because the power of the statistical tests was based on moderate sample sizes (i.e., 62 individual growth rates calculated during a single annual transition). Previous studies that implemented the same growth models that we used here (Von Bertalanffy, logistic-by-length, and logistic-by-weight) have shown that when the 3 models are applied to large sample sizes (i.e., to $>100$ individual growth rates), all the resultant fits are usually high $\left(R^{2}>0.95\right)$ and similar among the models (Dunham 1978, Watkins 1996, Sears 2005). In our case the fits were in general relatively low $\left(R^{2}<0.45\right)$ and relatively different among the models $\left(0.41<R^{2}<0.25\right.$; Table 1$)$, which may be explained by our small, although still considerable, sample size. Though we believe that our results might not be qualitatively different, more precise estimates and statistical results, along with stronger conclusions, would result from larger samples and data for more years.

In addition, the constructed growth curves resulted from a stationary growth model that does not consider temporal variation in the body growth pattern, such as periods of diminished growth due to environmental constraints (e.g., during winter). Therefore, estimates derived from growth curves, such as estimated ages at maturity, should be interpreted cautiously, even though S. m. mucronatus still exhibits activity during winter months (Salazar 2003, Toledo 2005) in comparison with other temperate-zone Sceloporus species that exhibit extreme winter dormancy and negligible growth during such months (Sears and Angilletta 2004, Cox 2006). In fact, 11 of our 62 estimated individual growth rates were 
calculated between December 2003 and February 2004, which indicates that positive body growth occurs during winter months in this subspecies. However, a certain degree of variation within the year in individual growth rates should exist, and the constructed growth curves do not account for such variation. In spite of the mentioned limitations, our growth analysis and interpretations represent a 1st and important model-based attempt to understand the general body growth pattern of this endemic subspecies.

\section{Demography}

Overall annual survival probability is notably high (0.781), especially compared with that of other species in the genus (0.01-0.53 annual survival rates in most Sceloporus species; Dunham et al. 1988, Clobert et al. 1998). A combination of high availability of safe refuges (rock crevices) in the study site and lack of a large number of predators in this high-altitude site (3375 m; Uribe-Peña et al. 1999) might explain such high survival rates in all size classes. In addition, S. m. mucronatus belongs to the torquatus group, which is composed of large-bodied species (Sites et al. 1992) that might be expected to show enhanced survival probabilities in comparison with smaller species (Tinkle et al. 1970, Dunham et al. 1988, Clobert et al. 1998). Therefore, the high survival rates observed in this population of S. m. mucronatus might be at least partially explained by phylogenetic effects.

We do not discard the possibility of a small artifact in our high survival estimates due to a relatively small sample size (we followed 69 resident lizards throughout 1 year; Table 2) in comparison with other studies on lizard demography that have relied on larger sample sizes (e.g., Blomberg and Shine 2001, McCoy et al. 2004, Iverson et al. 2006). However, because we were able to follow most of the resident lizards that inhabit a well-delimited study area (1 ha), we can argue that our survival estimates are reliable enough to provide confident interpretations.

The estimated population growth rate for the annual period studied indicated a considerable potential for population growth $(\lambda=$ $1.769 \pm 0.393)$. Nevertheless, maximum population size might be constrained by refuge availability given that rock crevices represent a fundamental resource (as refuges) for the sur- vival of these saxicolous lizards. In addition, given that the social system appears to be based on territories (i.e., a good territory with good refuges might increase the frequency of mating opportunities for males; Salazar 2003, Toledo 2005), individual reproductive success, and therefore the total number of newborns produced in the population, might also depend to a certain degree on crevice availability. In this sense, population growth and size should depend on the finite number of available adequate refuges on the site.

In contrast, given the observed high potential for numerical increase, it is possible that the population should have been in some sort of a comeback mode, which means that during the studied period the population might have been experiencing recovery from a deep decline. Unfortunately, we could not obtain information about the timing of the last catastrophic event in the site that could have caused such decline. Nevertheless, personal communication with people currently inhabiting areas close to the site (within the borders of the national park El Ajusco) led us to the conclusion that humaninduced fires to improve cattle forage are relatively common on the site and such fires can negatively affect the demographic behavior of lizard populations (Letnic et al. 2004).

In this sense we recognize that our results are derived from the projection of the observed demographic conditions in a particular annual transition; thus, we could not discard the possibility of considerable environmental variation among years, which can result in drastic variability in the demographic behavior of this population (Bierzychudek 1999, Mandujano et al. 2001). Assessing the probability of long-term persistence of this population requires exploration of long-term temporal variability in its quantitative dynamics, thus dealing with the restriction of the time-invariant matrix model (de Kroon et al. 2000). The observation that observed size-class structure was significantly different than the one expected under stable conditions suggests that the population is currently experiencing considerable fluctuations among years.

Nevertheless, our 1-year demographic data allowed us to characterize the demographic strategy of the lizards from this population. Growth of juveniles was the vital rate that contributed the most to population growth rate, followed by fecundity and stasis of the 1st 
reproductive category (adults I; Table 3). Thus, the vital rates involved in early reproduction (juveniles growing and reaching the 1st adult size class in which they reproduce) are the rates most important to the average fitness of this population (population growth rates have been interpreted as measures of average fitness [Benton and Grant 1999]). In contrast, fecundity and survival of old, large adults (adults II) contributed negligibly to population growth rate (Table 3). When analyzing elasticities per size class this pattern is also evident: whereas relative importance of juveniles and adults I is high, that of adults II is strikingly lower (Table 4). A plausible explanation of this pattern is that populations with $\lambda$ values considerably above unity are usually associated with high elasticities for growth and fecundity of young or small size classes (Silvertown et al. 1996, de Kroon et al. 2000). However, the near-to-zero elasticity values associated with adults II demand attention, mostly because survival in this size class is also high (0.666) as it is in the other categories $(0.783$ and 0.895 for juveniles and adults I, respectively), and because estimated fecundity is even higher than that of adults I (mean litter size was 3.89 for adults II and 2.92 for adults I). Further explanation is necessary for these low elasticity values.

A clear comprehension of patterns observed in the demographic strategy of the population, such as nearly equal contributions of fecundity, growth, and permanence to population growth rate or the low importance of large adults, cannot be achieved until other populations of the species are studied demographically. Once information is available for other populations, it will be possible to relate interpopulation demographic variation to variation in geographic and environmental conditions, so that determinants of variation in the demographic strategies can be identified (Silvertown et al. 1996). Similarly, the potential for numerical growth of $S . m$. mucronatus, based on the population we studied, cannot be considered conclusive until temporal (i.e., interannual) variation in the demographic behavior is accounted for.

\section{Conservation}

Sceloporus mucronatus is not even listed as endemic by the Mexican environmental agency (Secretaría de Medio Ambiente y Recursos Naturales, NOM-059-ECOL-2001), even though the species is only found in Mexico (Sites et al. 1992). Furthermore, the subspecies S. m. mucronatus has a distribution restricted to a narrow range around the rapidly expanding Mexico City (Salazar 2003, Toledo 2005). Thus, we strongly suggest the inclusion of this species and its subspecies as endemic in the list of species protected by the Mexican government (NOM-059-ECOL-2001). Even though our results do not suggest the necessity of a more specific conservation status for S. m. mucronatus, its endemicity and restricted distribution in central Mexico, where human activities and consequent habitat destruction are increasing, demand quantitative evaluation and monitoring of its populations.

\section{ACKNOWLEDGMENTS}

We thank the Secretaría de Medio Ambiente y Recursos Naturales-Mexico for providing the permit for field work (No. FAUT0074). G. Zamora-Abrego, M. Calderón-Espinosa, I. Rojas-González, and I. Rubio-Pérez kindly provided field and laboratory assistance. J. Johnson, S. Aird, and 2 anonymous reviewers provided comments that helped us to considerably improve an earlier version of the manuscript.

\section{Literature Cited}

Alvarez-Buylla, E.R., AND M. Slatkin. 1991. Finding confidence limits on population growth rates. Trends in Ecology and Evolution 6:221-224.

Anderson, R.A., AND L.J. ViTT. 1990. Sexual selection versus alternative causes of sexual dimorphism in teiid lizards. Oecologia 84:145-157.

AnDREws, R.M. 1982. Patterns of growth in reptiles. Pages 272-320 in C. Gans and F.H. Pough, editors, Biology of the Reptilia. Volume 13. Physiology D. Academic Press, New York.

BALlinger, R.E. 1973. Comparative demography of two viviparous iguanid lizards (Sceloporus jarrovi and Sceloporus poinsetti). Ecology 54:269-283.

Benton, T.G., AND A. Grant. 1999. Elasticity analysis as an important tool in evolutionary and population ecology. Trends in Ecology and Evolution 14:467-471.

BierzychudeK, P. 1999. Looking backwards: assessing the projections of a transition matrix model. Ecological Applications 9:1278-1287.

Blomberg, S.P., AND R. SHine. 2001. Modelling life history strategies with capture-recapture data: evolutionary demography of the water skink Eulamprus tympanum. Austral Ecology 26:349-359.

Caswell, H. 2001. Matrix population models. 2nd edition. Sinauer, Sunderland, MA.

Clobert, J., T. Garland, and R. Barbault. 1998. The evolution of demographic tactics in lizards: a test of somehypotheses concerning life history evolution. Journal of Evolutionary Biology 11:329-364. 
Contreras, C., and T. Valverde. 2002. Evaluation of the conservation status of a rare cactus (Mammillaria crucigera) through the analysis of its population dynamics. Journal of Arid Environments 51:89-102.

Cox, R.M. 2006. A test of the reproductive cost hypothesis for sexual size dimorphism in Yarrow's spiny lizard Sceloporus jarrovi. Journal of Animal Ecology 75: 1361-1369.

Crouse, D.T., L.B. Crowder, and H. Caswell. 1987. A stage-based population model for loggerhead sea turtles and implications for conservation. Ecology 68: 1412-1423.

de Kroon, H., A. Plaisier, J.M. van Groenendael, and H. CASWELL. 1986. Elasticity: the relative contribution of demographic parameters to population growth rate. Ecology 67:1427-1431.

de Kroon, H., J.M. van Groenendael, and J. Ehrlén. 2000. Elasticities: a review of methods and model limitations. Ecology 81:607-618.

Dunham, A.E. 1978. Food availability as a proximate factor influencing individual growth rates in the iguanid lizard Sceloporus merriami. Ecology 59:771780 .

Dunham, A.E., D.B. Miles, And D.N. Reznik. 1988. Life history patterns in squamate reptiles. Pages 443-551 in C. Gans and R.B. Huey, editors, Biology of the Reptilia. Volume 15. Academic Press, New York.

Dunham, A.E., D.W. Tinkle, and J.W. Gibbons. 1978. Body size in island lizards: a cautionary tale. Ecology 59:1230-1238.

Flores-Villela, O. 1993. Herpetofauna Mexicana. Annotated list of the species of amphibians and reptiles of Mexico, recent taxonomic changes, and new species. Carnegie Museum of Natural History, Special Publication No. 17, Pittsburgh, PA.

Gross, M.R. 1996. Alternative reproductive strategies and tactics: diversity within sexes. Trends in Ecology and Evolution 11:92-98.

Hedrick, A.V., And E.J. Temeles. 1989. The evolution of sexual dimorphism in animals: hypotheses and tests. Trends in Ecology and Evolution 4:136-138.

Iverson, J.B., S.J. Converse, G.R. Smith, And J.M. VALIULIS. 2006. Long-term trends in the demography of the Allen Cays rock iguana (Cyclura cychlura inornata): human disturbance and density-dependent effects. Biological Conservation 132:300-310.

Letnic, M., C.R. Dickman, M.K. Tischler, B. Tamayo, AND C.-L. BEH. 2004. The responses of small mammals and lizards to post-fire succession and rainfall in arid Australia. Journal of Arid Environments 59:85114.

Mandujano, M.C., C. Montaña, M. Franco, J. Golubov, AND A. FLORES-MARTínez. 2001. Integration of demographic annual variability in a clonal desert cactus. Ecology 82:344-359.

McCoy, E.D., P.P. HaRTMann, And H.R. Mushinsky. 2004. Population biology of the rare Florida scrub lizard in fragmented habitat. Herpetologica 60:54-61.

Méndez-de la Cruz, F.R., L.J. Gillette, Jr., M. Villagrán-Santa Cruz, and G. Casas-Andreu. 1988. Reproductive and fat body cycles of the viviparous lizard, Sceloporus mucronatus (Sauria: Iguanidae). Journal of Herpetology 22:1-12.

Méndez-de la Cruz, F.R., M. Villagrán-Santa Cruz, AND O. Cuellar. 1994. Geographic variation of spermatogenesis in the Mexican viviparous lizard Sceloporus mucronatus Biogeographica 70:59-67.
Mesterton-Gibbons, M. 1993. Why demographic elasticities sum to one: a postscript to de Kroon et al. Ecology 74:2467-2468.

Niewiarowski, P.H., M.J. Angilletta, Jr., and A.D. LEACHÉ. 2004. Phylogenetic comparative analysis of life-history variation among populations of the lizard Sceloporus undulatus: an example and prognosis. Evolution 58:619-633.

Norma Oficial Mexicana. 2001. (NOM-059-ECOL2001). Protección ambiental. Especies nativas de México de flora y fauna silvestres. Categorías de riesgo y especificaciones para su inclusión, exclusión o cambio. Lista de especies en riesgo. Diario Oficial de la Federación, Instituto Nacional de Ecología, México.

Olsson, M., And T. Madsen. 1998. Sexual selection and sperm competition in reptiles. Pages 503-569 in T.R. Birkhead and A.P. Møller, editors, Sperm competition and sexual selection. Academic Press, London.

Pough, F.H., R.M. Andrews, J.E. Cadle, M.L. Crump, A.H. SAVITZKY, AND K.D. Wells. 2004. Herpetology. 3rd edition. Pearson Prentice Hall, NJ.

Ramírez-Bautista, A., E. Jiménez-Cruz, and J.C. MarSHALL. 2004. Comparative life-history for populations of the Sceloporus grammicus complex (Squamata: Phrynosomatidae). Western North American Naturalist 64:175-183.

SALAZAR, D. 2003. Estudio de la reproducción y alimentación de Sceloporus mucronatus (Sauria: Phrynosomatidae) en el sistema modificado de San José Deguedo, Estado de México. Bachelor thesis, Facultad de Estudios Superiores Iztacala, Universidad Nacional Autónoma de México.

Schoener, T.W., AND A. Schoener. 1978. Estimating and interpreting body-size growth in some Anolis lizards. Copeia 1978:390-405.

SEARs, M.W. 2005. Geographic variation in the life history of the sagebrush lizard: the role of thermal constraints on activity. Oecologia 143:25-36.

Sears, M.W., and M.J. Angilletta, Jr. 2004. Body size clines in Sceloporus lizards: proximate mechanisms and demographic constraints. Integrative and Comparative Biology 44:433-442.

SHine, R. 1989. Ecological causes for the evolution of sexual dimorphism: a review of the evidence. Quarterly Review of Biology 64:419-433.

Silvertown, J., M. Franco, and E. Menges. 1996. Interpretation of elasticity matrices as an aid to the management of plant populations for conservation. Conservation Biology 10:591-597.

Silvertown, J., M. Franco, I. Pisanty, and A. Mendoza. 1993. Comparative plant demography-relative importance of life-cycle components to the finite rate of increase in woody and herbaceous perennials. Journal of Ecology 81:465-476.

Sinervo, B., AND C.M. LiveLy. 1996. The rock-paper-scissors game and the evolution of alternative male strategies. Nature 380:240-243

Sites, J.W., Jr., J.W. Archie, C.J. Cole, and O. FloresVilLELA. 1992. A review of phylogentic hypotheses for lizards of the genus Sceloporus (Phrynosomatidae): implications for ecological and evolutionary studies. Bulletin of the American Museum of Natural History 213:1-110.

Stamps, J.A. 1993. Sexual size dimorphism in species with asymptotic growth after maturity. Biological Journal of the Linnean Society 50:123-145. 
1999. Relationships between female density and sexual size dimorphism in samples of Anolis sagrei. Copeia 1999:760-765.

StEarns, S.C. 1992. The evolution of life histories. Oxford University Press, New York.

Tinkle, D.W., A.E. Dunham, and J.D. Congdon. 1993. Life history and demographic variation in the lizard Sceloporus graciosus: a long-term study. Ecology 74: 2413-2429.

Tinkle, D.W., H.M. Wilbur, and S.G. Tilley. 1970. Evolutionary strategies in lizard reproduction. Evolution 24:55-74.

Toledo, A. 2005. Variación morfométrica de dos poblaciones de Sceloporus mucronatus mucronatus Coopem 1885 (Squamata: Phrynosomatidae) de ambientes contrastantes. Bachelor thesis, Universidad Veracruzana, México.

Uribe-Peña, Z., A. Ramírez-Bautista, and G. CasasANDREu. 1999. Anfibios y reptiles de las serranías del Distrito Federal, México. Cuadernos del Instituto de Biología. Volume 32. Universidad Nacional Autónoma de México.

Villagrán-Santa Cruz, M., F.R. Méndez-De la Cruz, AND L. ParRa-GÁmEz. 1994. Ciclo espermatogénico del lacertilio Sceloporus mucronatus (Reptilia: Phrynosomatidae). Revista de Biología Tropical 42:289-296.

VITT, L.J. 1982. Sexual dimorphism and reproduction in the microteiid lizard, Gymnophthalmus multiscutatus. Journal of Herpetology 16:325-329.

Von Bertalanffy, L. 1951. Metabolic types and growth types. American Naturalist 85:111-117.

1957. Quantitative laws in metabolism and growth. Quarterly Review of Biology 32:217-231.

WatKINS, G.G. 1996. Proximate causes of sexual size dimorphism in the iguanian lizard Microlophus occipitalis. Ecology 77:1473-1482.

ZúÑIga-VEGA, J.J., R.I. Rojas-GonZÁleZ, J.A. LemosEspinal, AND M.E. PÉrez-Trejo. 2005. Growth ecology of the lizard Xenosaurus grandis in Veracruz, México. Journal of Herpetology 39:433-443.

Zúniga-Vega, J.J., T. Valverde, R.I. Rojas-GonZález, AND J.A. Lemos-Espinal. 2007. Analysis of the population dynamics of an endangered lizard (Xenosaurus grandis) through the use of projection matrices. Copeia 2007:324-335.

Received 28 June 2006 Accepted 6 February 2007 